Research Article

\title{
The Influence of Longitudinal Force on the Internal Force Distribution and Deformation Coordination Mechanism for Segment Lining
}

\author{
Cao Songyu $\mathbb{D}^{\mathbb{D}},{ }^{1}$ Feng Kun $\mathbb{D}^{1},{ }^{1}$ Liu Xun, ${ }^{1}$ He Chuan, ${ }^{1}$ and Xiao Mingqing ${ }^{2,3}$ \\ ${ }^{1}$ Key Laboratory of Transportation Tunnel Engineering, Ministry of Education, Southwest Jiaotong University, \\ Chengdu 610031, China \\ ${ }^{2}$ China Railway Siyuan Survey and Design Group Co. Ltd., Wuhan, Hubei 430071, China \\ ${ }^{3}$ National \& Local Joint Engineering Research Center of Underwater Tunnel Technology, Wuhan, Hubei 430071, China \\ Correspondence should be addressed to Feng Kun; kfeng123@163.com
}

Received 17 December 2020; Revised 21 January 2021; Accepted 25 January 2021; Published 4 February 2021

Academic Editor: Mingfeng Lei

Copyright (c) 2021 Cao Songyu et al. This is an open access article distributed under the Creative Commons Attribution License, which permits unrestricted use, distribution, and reproduction in any medium, provided the original work is properly cited.

\begin{abstract}
A series of local prototype tests are conducted on the Sutong GIL (Gas-Insulated Line) and Shiziyang Tunnel. These tests investigate the redistribution law of segment deformation and the bending moment during construction. The results reveal that the transfer ability of deformation and the bending moment improve with an increase in the longitudinal force. Stage characteristics are observed for the effect of the longitudinal force on the opening of the circumferential joints. Segments are fully contacted for the circumferential joints when the joint opening is not observed. The frictions between the segments are the key factors for the bending moment and segment deformation control. The opening of the circumferential joint with an increase in the joint opening then becomes the primary control factor. The transfer ability becomes stable when the load continues increasing after mortise and tenon contact. Better transfer ability occurs with a general segment with four pairs of mortises and tenons. This was presented as a smaller value of an increasing rate and the stable magnitude of the joint opening. From the perspective of practical engineering, mortises and tenons can be added to the vault to increase the load and deformation transfer ability of the general segment after the loss of the longitudinal force.
\end{abstract}

\section{Introduction}

In shield tunnels, the longitudinal force and the connection of the segment joints significantly influence the coordination of the internal force distribution and the displacement of the combined segment structure $[1,2]$. In engineering, the uncoordinated deformation of different segments in the ring direction is often caused by the interring dislocation, which affects the uniform distribution of the load in the longitudinal direction of the segment. Therefore, improving the longitudinal restraint force and selecting the appropriate ring joint structure represent an effective way to improve the dislocation deformation and force between the rings under this condition. The segment ring joint structure directly impacts the ring dislocation and the ring joint opening. During the jacking process of the construction period, when the longitudinal force is reduced during the operation period, the dislocation between the rings and the opening of the ring joints are directly related to the longitudinal restraint force. Therefore, it is the essence of the research content to discover the interaction relationship and mechanism of the structural form of the circumferential joint, the longitudinal force, the opening of the circumferential joint and the internal force distribution, and deformation of the structure.

Many studies have investigated the effect of the longitudinal force between the segments and the structure of the circumferential joint. Scholars have studied the influence of jack thrust on the internal force of the structural segments during the construction period and obtained the corresponding influence method [3-8]. Relying on the Qianjiang Tunnel Project, Men et al. [9] conducted a theoretical 
analysis and clarified the influence of the longitudinal stress of the shield tunnel on the leakage of the tunnel. The prototype test in Biwei et al.'s work [10] was based on the Shanghai Qingcao Water Tunnel. It clarified how the bending moment adjustment coefficient is affected by radial and axial forces. Li et al. [11] clarified the influence of longitudinal force and bolt yield on the longitudinal flexural rigidity of the lining structures through the finite element model and theoretical analysis.

Zhang et al. [12] analyzed the effect of the longitudinal bolt pretightening force on the longitudinal stiffness in a linear increasing relationship through a theoretical analysis and numerical simulation. Zhang et al. [13] determined the relationship between the longitudinal force and the bending moment transmission coefficient. Kun et al. [14] discussed the influence of the longitudinal force on the internal force of the segment. Peng et al. [15] relied on the combination of experimental verification and numerical calculations on Beijing Metro Line 14. The results revealed the mechanical influence law of the longitudinal force on the block-type capping block. Zhu et al. [16-19] clarified the mechanical properties of the tunnel ring joints under the combined action of the axial force and shear force through a data analysis.

Zhang et al. [20] analyzed the mechanism of the bending moment transfer coefficient and its influencing modes and factors through a finite element model. The relationship between them was discussed. Liu et al. [21] explored the corresponding shear mechanism of joints under the combined action of an axial force and shear force through prototype experiments. Dongmei et al. [22] obtained the calculation formula for the shear stiffness of the circumferential joint and the friction coefficient value of the contact surface based on the prototype test of the Shanghai Yangtze River Tunnel. Tang [23] combined the finite element model and theoretical methods to derive the relationship between the opening of the circumferential joint, the longitudinal stiffness, and the radius of curvature of the segment structure.

For the structural form of the circumferential joint, Zhang et al. [24] took the longitudinal joints of the shield tunnel segments of the Tianjin Binhai Line Z2 as the research object into account. They analyzed and compared the three joints of straight bolts, oblique bolts, and bent bolts at different bending moments and axes. The mechanical properties of segment joints are discussed. Liu et al. [25] completed a flexural mathematical model on the characteristics of the segment joints of large-section shield tunnels with complex joint surfaces. The model can express concrete crack propagation, compression, bolt yield, and joint failure on the segment joint surface.

Salemi et al. [26] studied the shear process and crosssectional deformation of the circumferential joint, the internal force of the bolts at different positions, and the mechanical behavior of the mortise and tenon. Guo et al. [27] carried out a three-ring full-scale test and a circumferential joint shear test on the joints of the subway shield tunnel segments. They studied the deformation development law and mechanical properties of the joints of curved bolts with mortises and tenons. Cao et al. [28] discussed the influence of longitudinal force on the internal force of the structure based on an Abaqus finite element.

The literature reveals that the influence of longitudinal restraint forces on the displacement coordination and internal force distribution between the segments is rarely involved. In addition, the influence of different ring connection methods on the internal force distribution and deformation coordination of the segment is still unclear. The selection of the connection between the segments and the structure in the tunnel design, as well as the influence of the longitudinal force changes during the construction and operation periods on the overall force of the structure, need to be clarified. The local prototype test method is used to study the local segment structure under different longitudinal forces. This is based on the new type of ring connection used in the Foguan-Shiziyang project shield tunnel and the Sutong GIL comprehensive pipe gallery shield tunnel. The internal force distribution laws of the three-tenon and fourtenon type segments are compared. The influence of the longitudinal force and ring connection structure on the force transmission performance and displacement coordination mechanism between the segments is also explored.

\section{Overview of the Longitudinal Connection of the Segment Structure}

This paper focuses on the influence mode of the mortise and tenon between the rings in the loading process. The internal force distribution and displacement transmission capacity between the segment rings are also explored. In existing tunnels, the main restraint methods between the general block rings include the three-tenon distributed, four-tenon distributed, and full-ring long tenons. Table 1 presents some of the circumferential joint forms for existing tunnels. These different mortise and tenon forms have their own characteristics in terms of economy, ease of assembly, and integrity. For tunnel structures, structural safety and load-bearing performance are particularly important. In addition, the connection between the rings directly affects the integrity of the structure during the construction process. Therefore, it is particularly critical to determine the overall mechanical performance of the structure under the different layouts of the mortise and tenon between the rings and analyze the influencing factors.

\section{Experimental Design}

3.1. Test Object. To ascertain the influence of different ring mortise and tenon forms on the overall mechanical performance of the segment structure under the action of the vault load and the longitudinal force, this paper adopts the "shield tunnel segment loading" device as shown in Figures 1(a) and 1(b). The loading capacity of the device in the vertical direction is $5000 \mathrm{kN}$, and it is $5000 \mathrm{kN}$ in the horizontal direction. It can carry out the bending, shear resistance, and joint mechanical properties of the shield tunnel prototype segment with a maximum diameter of $16 \mathrm{~m}$ and the segment lining failure loading test. 
TABLE 1: List of domestic representative joint structures of shield tunnels.

\begin{tabular}{|c|c|c|}
\hline Name & Tunnel details & Circumferential joint \\
\hline Wuhan Yangtze River Tunnel & $\begin{array}{l}\text { Length: } 2540 \mathrm{~m} \text {, inner diameter: } 10 \mathrm{~m} \text {, outer diameter: } 11 \mathrm{~m} \text {, } \\
\text { width: } 2 \mathrm{~m}\end{array}$ & $\begin{array}{l}\text { Full-ring mortises and } \\
\text { tenons }\end{array}$ \\
\hline Nanjing Yangtze River Tunnel & $\begin{array}{l}\text { Length: } 3020 \mathrm{~m} \text {, inner diameter: } 13.3 \mathrm{~m} \text {, outer diameter: } \\
14.5 \mathrm{~m} \text {, width } 2 \mathrm{~m}\end{array}$ & $\begin{array}{l}\text { Full-ring mortises and } \\
\text { tenons }\end{array}$ \\
\hline Chongming Tunnel in Shanghai & $\begin{array}{c}\text { Length } 8950 \mathrm{~m} \text {, inner diameter: } 13.7 \mathrm{~m} \text {, outer diameter: } 15 \mathrm{~m} \text {, } \\
\text { width: } 2 \mathrm{~m}\end{array}$ & $\begin{array}{l}\text { Full-ring mortises and } \\
\text { tenons }\end{array}$ \\
\hline Zhanjiang Bay Cross-Sea Tunnel & $\begin{array}{c}\text { Length: } 2750 \mathrm{~m} \text {, inner diameter: } 6 \mathrm{~m} \text {, outer diameter: } 5.1 \mathrm{~m} \text {, } \\
\text { width: } 1.5 \mathrm{~m}\end{array}$ & Two-tenon type \\
\hline Jinan Yellow River Tunnel & $\begin{array}{l}\text { Length: } 2519.2 \mathrm{~m} \text {, inner diameter: } 13.9 \mathrm{~m} \text {, outer diameter: } \\
15.2 \mathrm{~m} \text {, width: } 2 \mathrm{~m}\end{array}$ & Three-tenon type \\
\hline Ningbo Rail Transit & $\begin{array}{l}\text { LengthL59000 m, inner diameter: } 6.26 \mathrm{~m} \text {, outer diameter: } \\
\qquad 6.34 \mathrm{~m}\end{array}$ & Three-tenon type \\
\hline Hangzhou Qingchun Road Crossing tunnel & $\begin{array}{c}\text { Length: } 1763 \mathrm{~m} \text {, inner diameter: } 10.3 \mathrm{~m} \text {, outer diameter: } \\
11.3 \mathrm{~m} \text {, width: } 5.4 \mathrm{~m}\end{array}$ & Three-tenon type \\
\hline Sutton GIL Power Pipe Gallery Tunnel & $\begin{array}{c}\text { Length: } 5467 \mathrm{~m} \text {, inner diameter: } 10.5 \mathrm{~m} \text {, outer diameter: } \\
11.6 \mathrm{~m} \text {, width: } 2 \mathrm{~m}\end{array}$ & Three-tenon type \\
\hline $\begin{array}{l}\text { Lion Ocean Tunnel of Foguan-Dongguan } \\
\text { Intercity Railway }\end{array}$ & $\begin{array}{c}\text { Length: } 9340 \mathrm{~m} \text {, inner diameter: } 9.8 \mathrm{~m} \text {, outer diameter: } \\
10.8 \mathrm{~m} \text {, width: } 2 \mathrm{~m}\end{array}$ & Four-tenon type \\
\hline
\end{tabular}

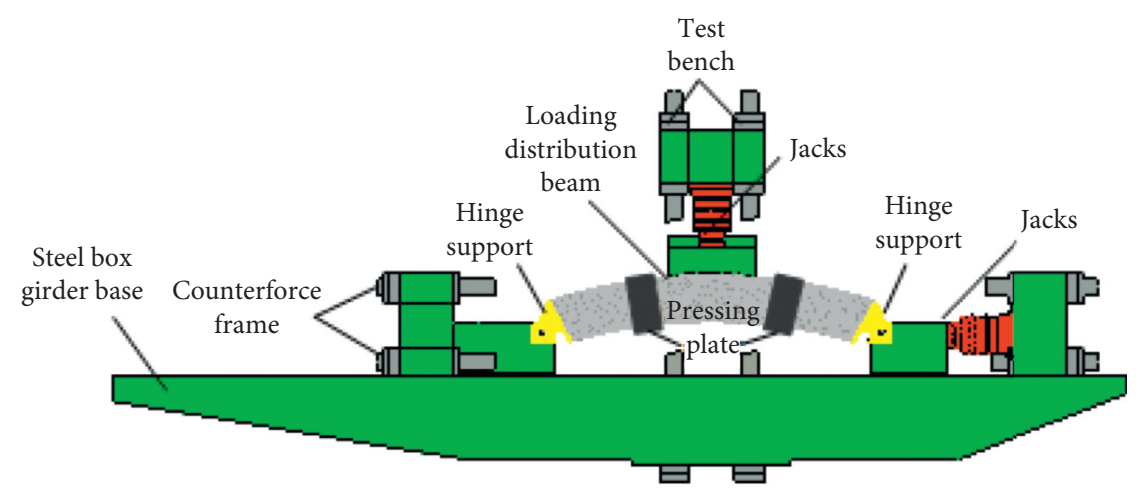

(a)

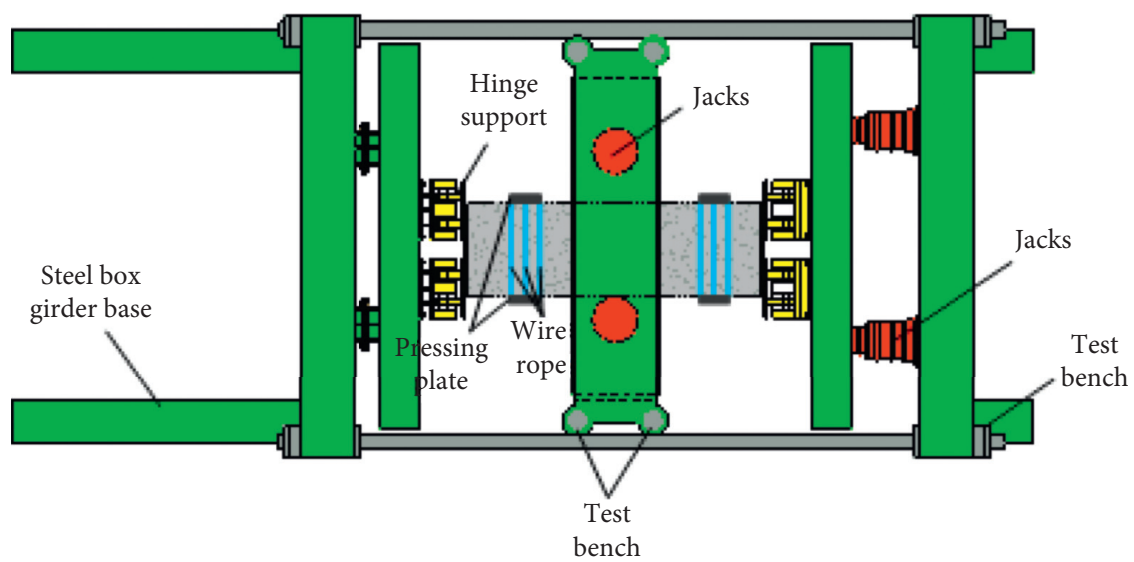

(b)

FIgURE 1: Three-dimensional diagram of pipe slice loading. (a) Front view. (b) Top view.

(A) Sutong GIL Power Pipe Gallery Tunnel Project: The tunnel structure uses a C60 concrete pouring segment lining structure, with an outer diameter of $11.6 \mathrm{~m}$, an inner diameter of $10.5 \mathrm{~m}$, a width of $2 \mathrm{~m}$, and a thickness of $0.55 \mathrm{~m}$. There are a total of 24 circumferential bolts M36 in the segment structure and 22 longitudinal bolts M40 between the rings. The angle between the longitudinal bolts is $16.3636^{\circ}$ (Figure 2(a)). (B) The Shiziyang Tunnel Project of the Foshan Intercity Railway: The tunnel structure uses a C60 


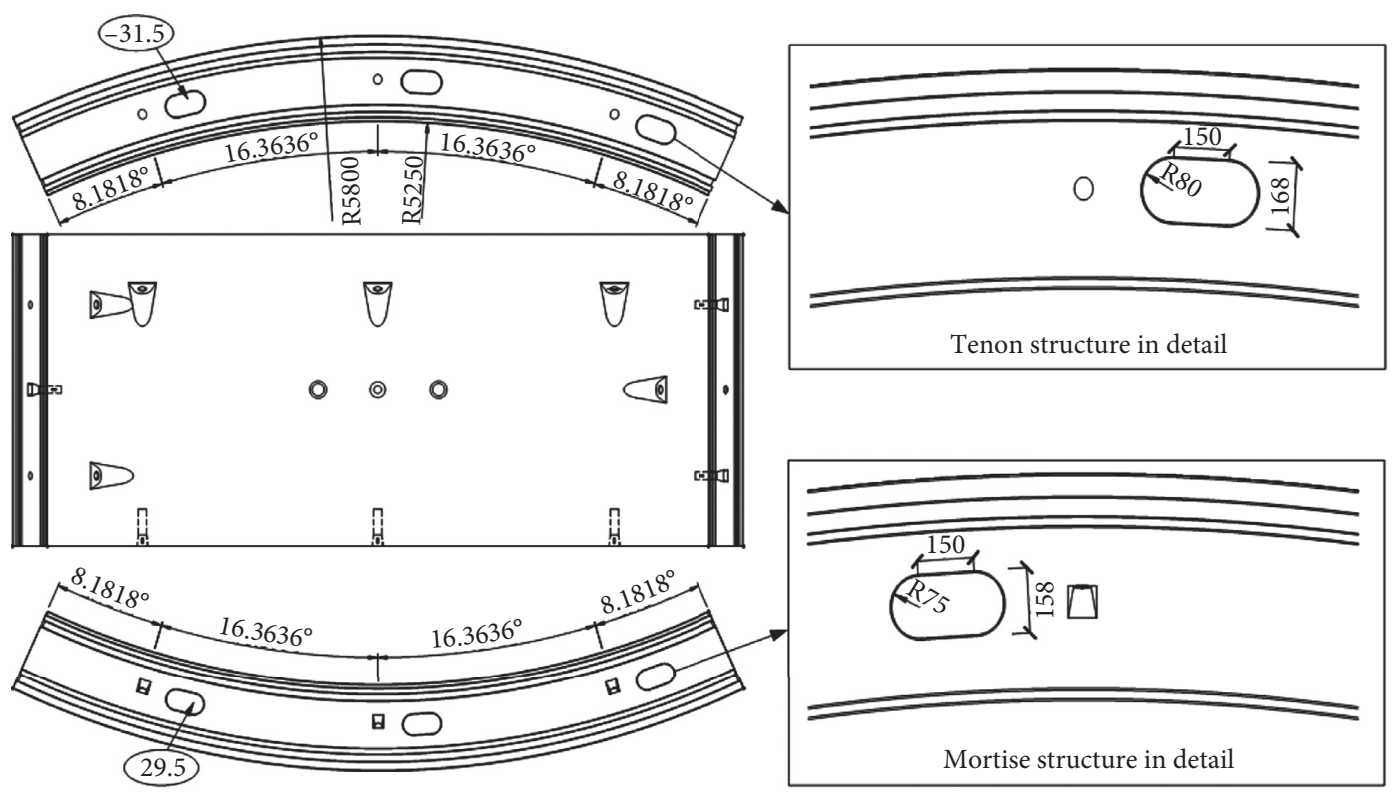

(a)

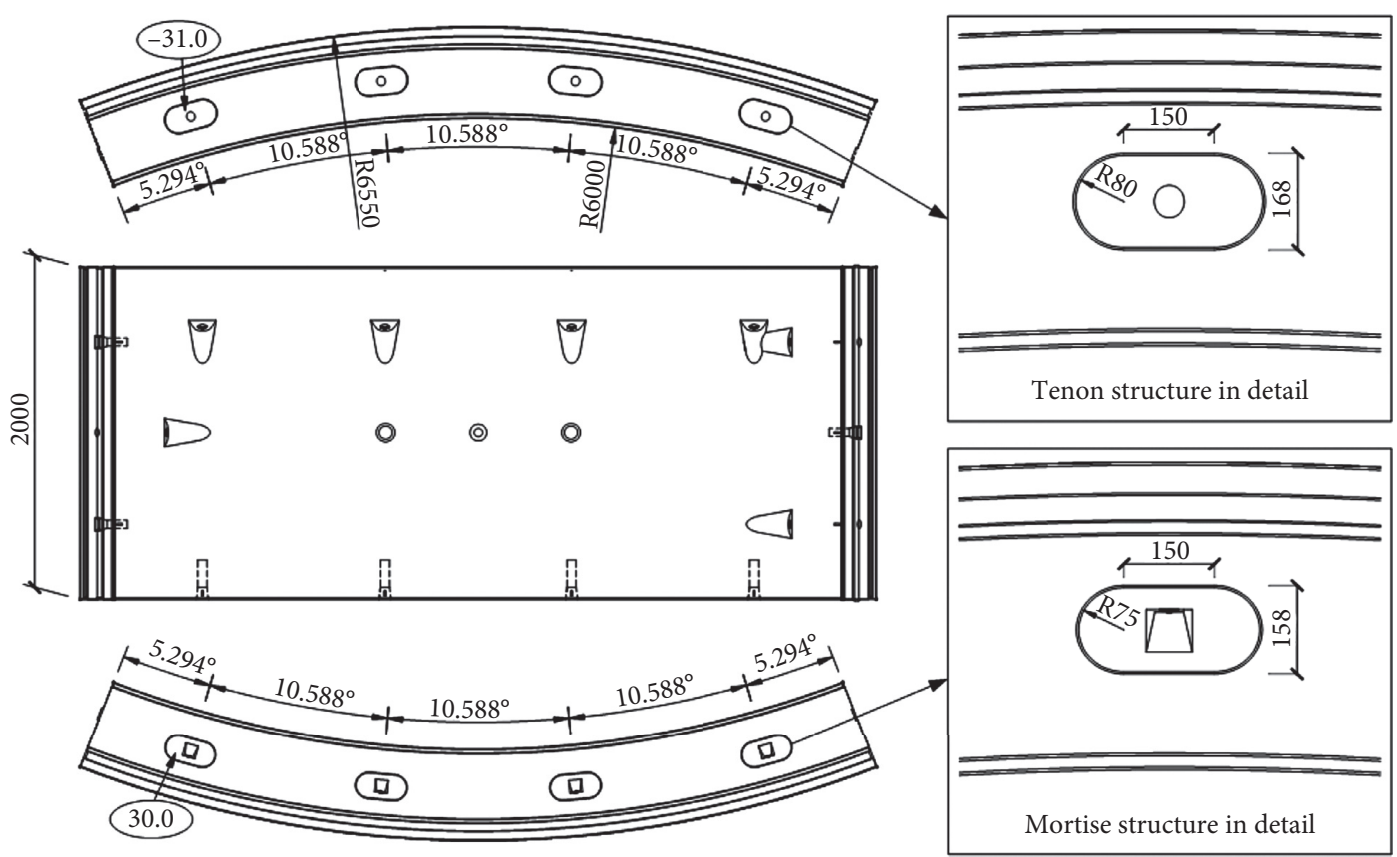

(b)

FIgUre 2: Schematic diagram of circumferential joints of test segments. (a) Sutong GIL Tunnel. (b) Foguan Tunnel.

concrete pouring segment lining structure, with an inner diameter of $12.0 \mathrm{~m}$, a width of $2 \mathrm{~m}$, and a thickness of $0.55 \mathrm{~m}$. The circumferential bolt of the segment structure adopts M36. The longitudinal bolt in the circumferential joint adopts M40 (Figure 2(b)).

3.2. Layout of Test Specimens and Measuring Points. The test device is illustrated in Figures 2 and 3. The load is transmitted to the steel plate and the structure through the anchor cable structure in the width direction of the segment. It is equipped with an anchor cable tension measuring device.
The left and right ends of the test piece are supported by rotating hinge supports. The test piece can rotate freely at the supports at both ends. Two sets of three-ring combined segment test pieces (i.e., B1 and B2 are adjacent ring clamping blocks $+\mathrm{B} 3$ middle block) were used in the test. The three-tenon and four-tenon universal segments are illustrated in Figure 4.

The experiment's measurement items include the internal force, vertical displacement, and concrete strain measurement of the segment structure. The joint opening and displacement are measured by a differential displacement sensor with an accuracy of $0.01 \mathrm{~mm}$. Figure 5 illustrates 


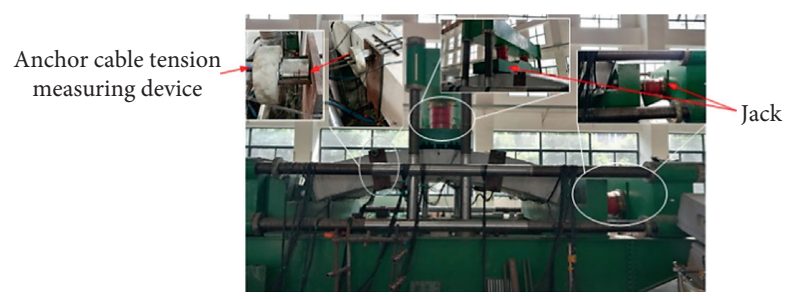

FIgURE 3: Segment loading test bench.

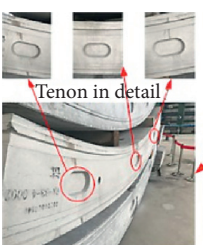

Tenon

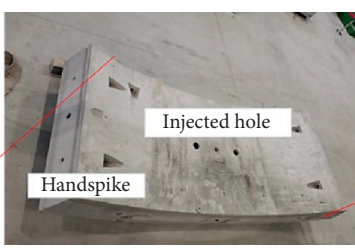

Single seam triple tenon type

(a)

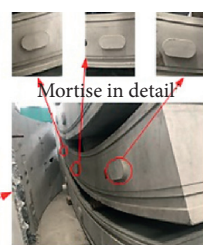

Mortise

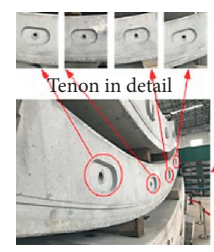

Tenon

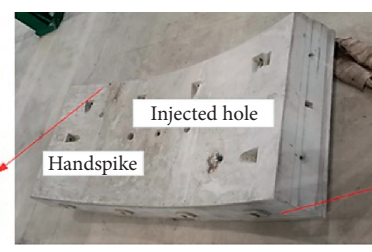

Single seam four-tenon type

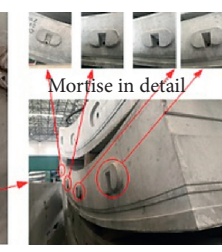

Mortise

(b)

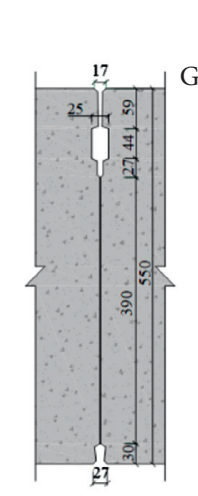

Girth structure 1
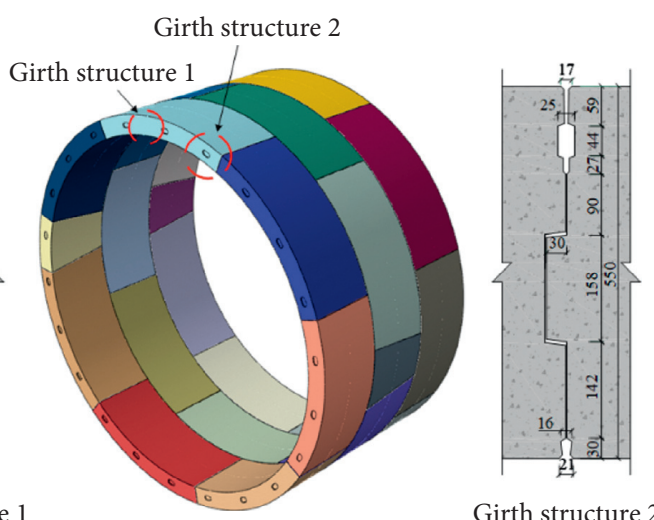

Girth structure 2

FIGURE 5: Detailed structure of circumferential joint.

the structure of the non-tenon-mortise cross section and the ring-mortise cross section at the circumferential joint. The measuring point layout is shown in Figure 6. For the multiring composite segment, 11 displacement gauges are arranged equidistantly on the arc surface of the vault. Overall, 7 points are arranged on the arc surface of the single segment. The strain gauge layout is presented in Figure 6. According to the calculation, the anchor cables are arranged symmetrically in the longitudinal direction. The longitudinal force is applied, while the longitudinal force is controlled by the YBY type through-core sensor. Figure 7 illustrates a detailed view of the internal reinforcement layout of the segment.

3.3. Test Conditions. Table 2 presents the loading table of a single segment. A total of 4 sets of loading conditions are set for a single segment. No longitudinal force is applied. To compare the internal force and displacement distribution of the three-tenon and the four-tenon type general segments,

the loading conditions of the two segment structures remain the same.

Table 3 illustrates the loading table of the combined segment. According to the experimental conditions, in order to maintain the structure in the normal stage, the longitudinal force is, respectively, selected (i.e., $600 \mathrm{kN}, 1000 \mathrm{kN}$, and $1400 \mathrm{kN}$ ) and the vertical load is, respectively, selected (i.e., $600 \mathrm{kN}, 1200 \mathrm{kN}, 1800 \mathrm{kN}$, and $2400 \mathrm{kN}$ ). Two loads are applied to the vault to compare and analyze the influence of the interring dislocation and better analyze the overall deformation of the structure. The longitudinal force and the vault load are, respectively, controlled under the conditions that the ring joint does not open and the opening occurs. At the same time, 4 groups of combined segments are set up with only vertical loading conditions. The loading and measuring principle are presented in $[29,30]$.

\section{Analysis of Test Results}

4.1. The Influence of the Longitudinal Force on the Deformation of B3 under Different Ring Connections. Figure 8 illustrates the width direction displacement of single segment piece and combined segment pieces. To evaluate the ability of displacement distribution for the middle segment to both sides, the displacement adjustment coefficient is defined as

$$
S=1-\frac{S_{1}}{S_{2}}
$$

In equation (1), $S_{1}$ is the displacement of the B3 block in the combined segment along the width direction and $S_{2}$ is the displacement of the single segment along the width direction. $S_{t}$ is the displacement adjustment coefficient of the universal B3 block for the three-tenon type and $S_{f}$ is the displacement adjustment coefficient of the universal B3 block for the four-tenon type. The values obtained from the test are summarized in Figure 9. 


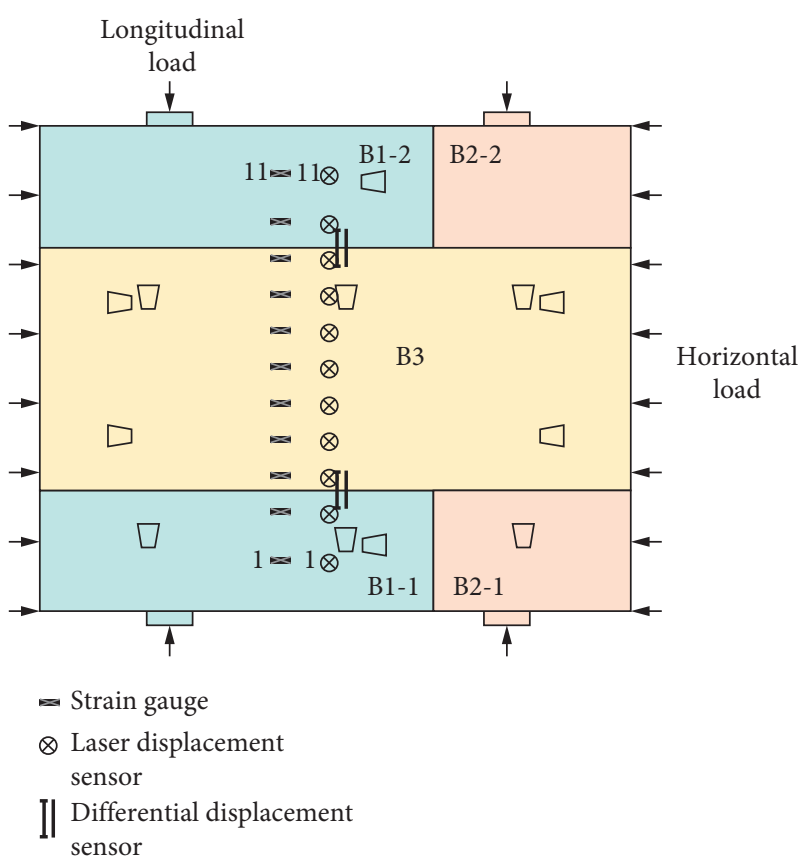

(a)

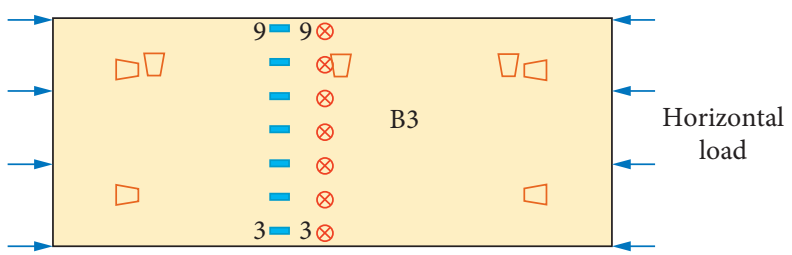

- strain gauge

$\otimes$ laser displacement sensor

FIgURE 6: Measuring points of segments. (a) Measuring points of combined segments. (b) Measuring points of single segment.

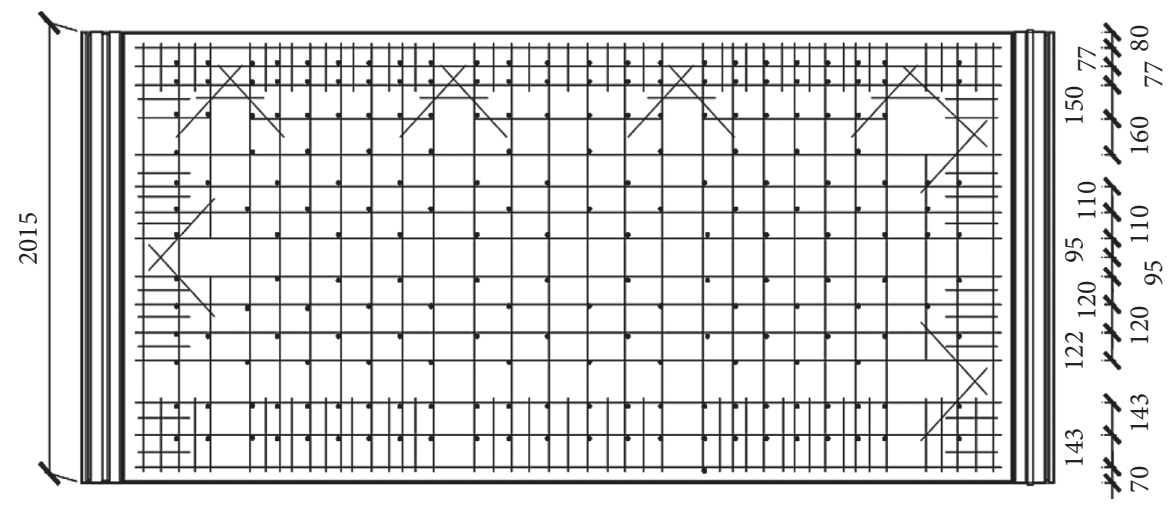

Figure 7: Steel bar of B3 segment.

TABLE 2: Loading cases of single segment.

\begin{tabular}{lccc}
\hline Circumferential joint form & Loading conditions & Longitudinal force $(\mathrm{kN})$ & Vertical load $(\mathrm{kN})$ \\
\hline \multirow{2}{*}{ Three-tenon type } & 21 & 0 & 600 \\
& 22 & & 1200 \\
& 23 & & 2400 \\
& 24 & 0 & 600 \\
Four-tenon type & 25 & 0 & 1200 \\
& 26 & & 1800 \\
& 27 & 2400 & 2400 \\
\hline
\end{tabular}

The working conditions (i.e., 21 24) in Figure 8(a) and the working conditions (i.e., 25 28) in Figure 8(b) are the vertical displacements of each measuring point under the condition of no longitudinal force. They correspond to the vertical loads (i.e., $600 \mathrm{kN}, 1200 \mathrm{kN}, 1800 \mathrm{kN}$, and $2400 \mathrm{kN}$ ). Figure 9 shows that the corresponding values for $S_{t}$ are 0.27 , $0.21,0.18$, and 0.13 and the values for $S_{f}$ are $0.32,0.27,0.25$, and 0.22 , respectively. For three-tenon and four-tenon 
TABLE 3: Loading cases of composite segment.

\begin{tabular}{|c|c|c|c|}
\hline Circumferential joint form & Working conditions & Longitudinal force $(\mathrm{kN})$ & Vertical load $(\mathrm{kN})$ \\
\hline \multirow{10}{*}{ Three-tenon type } & 1 & \multirow[t]{4}{*}{ 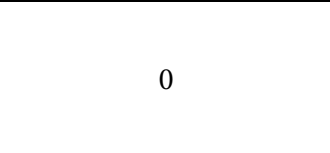 } & 600 \\
\hline & 2 & & 1200 \\
\hline & 3 & & 1800 \\
\hline & 4 & & 2400 \\
\hline & 5 & \multirow{2}{*}{600} & 600 \\
\hline & 6 & & 1200 \\
\hline & 7 & \multirow{2}{*}{1000} & 1200 \\
\hline & 8 & & 1800 \\
\hline & 9 & \multirow{2}{*}{1400} & 1800 \\
\hline & 10 & & 2400 \\
\hline \multirow{10}{*}{ Four-tenon type } & 11 & \multirow{4}{*}{0} & 600 \\
\hline & 12 & & 1200 \\
\hline & 13 & & 1800 \\
\hline & 14 & & 2400 \\
\hline & 15 & \multirow{2}{*}{600} & 600 \\
\hline & 16 & & 1200 \\
\hline & 17 & \multirow{2}{*}{1000} & 1200 \\
\hline & 18 & & 1800 \\
\hline & 19 & \multirow{2}{*}{1400} & 1800 \\
\hline & 20 & & 2400 \\
\hline
\end{tabular}

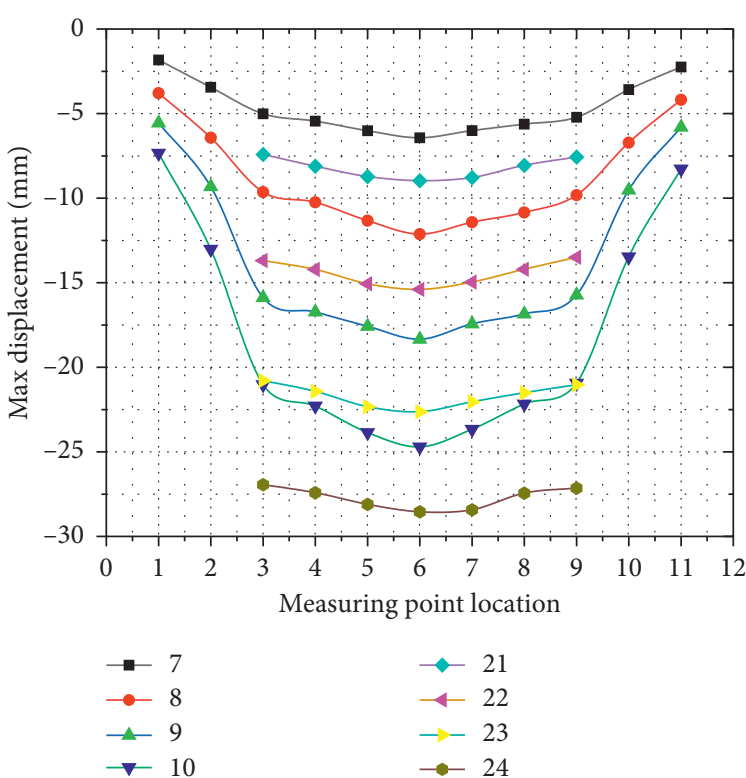

(a)

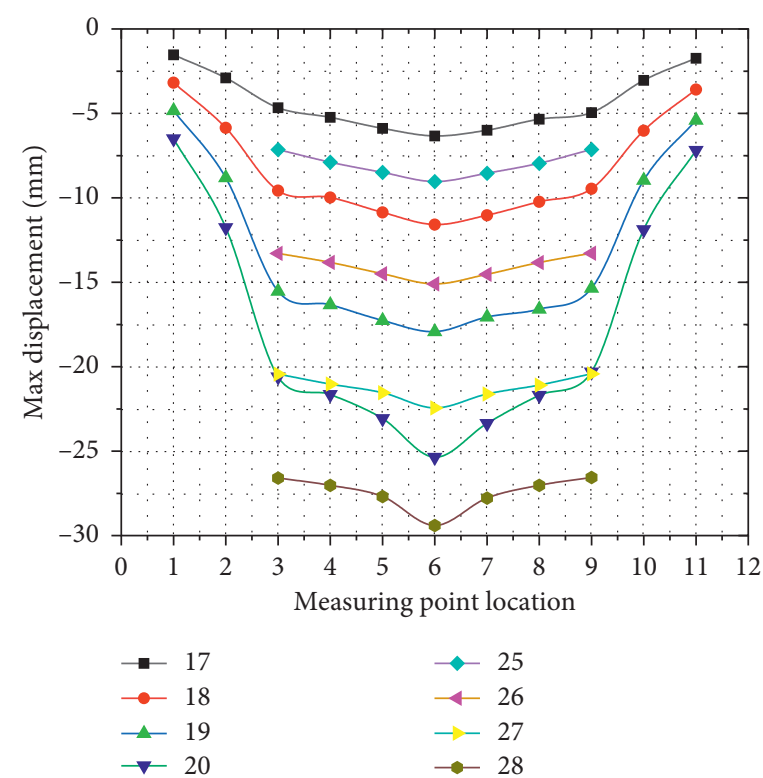

(b)

Figure 8: The maximum displacement of single segment and three segments along the width direction under vertical loads. (a) Maximum displacement of three-tenon type segment along width direction. (b) Maximum displacement of four-tenon type segment along width direction.

longitudinally connected segments, without a longitudinal force, the corresponding ring for the coordination capacity of the interdisplacement decreases with the increase in the vertical load. This indicates that the coordination capacity of the displacement between the segment rings decreases with the increase in the vertical load of the vault. Comparing $S_{t}$ and $S_{f}$, with the increase of the vertical load of the vault, the reduction of $S_{t}$ is greater, indicating that the three-tenon segment has a faster reduction in the displacement adjustment ability compared with four-tenon segment under the same load. Hence, the three-tenon segment will produce greater vertical deformation.

Figure 10 compares $S_{t}$ and $S_{f}$ of the working conditions (working conditions 5, 7, 9, 15, 17, and 19), where the ring joint dislocation does not occur. The values maintain good consistency. At this time, the displacement between the segments is adjusted. It is not affected by the arrangement of the mortises and tenons. Under this working condition, the longitudinal force further increases and the coordination of the displacement of the combined segment is not affected. 


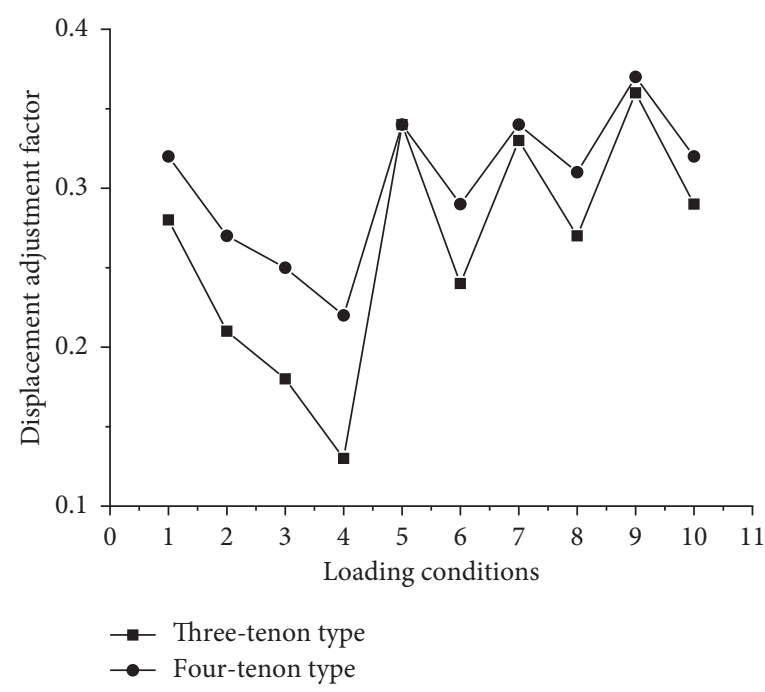

FIGURE 9: Results of displacement adjustment coefficient.

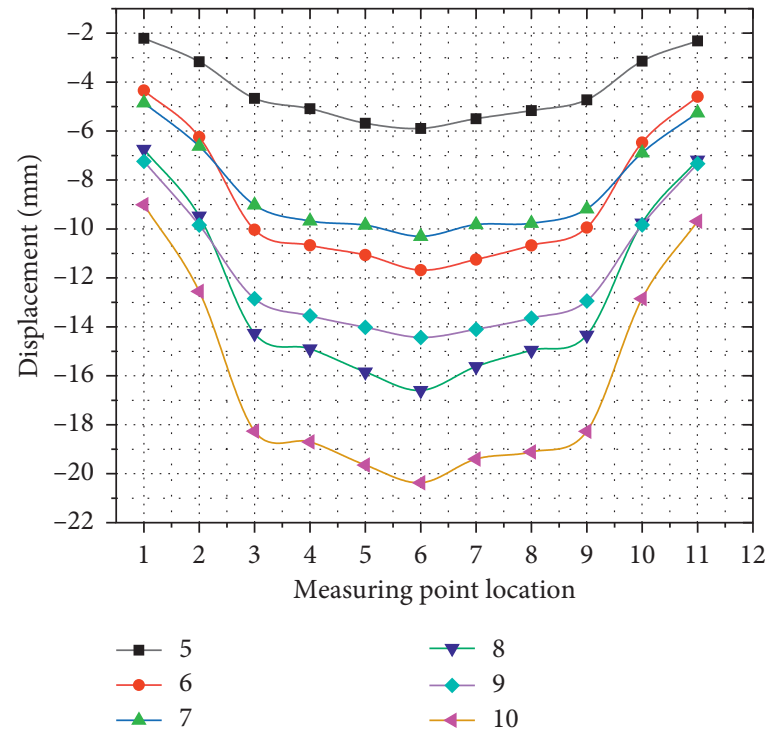

(a)

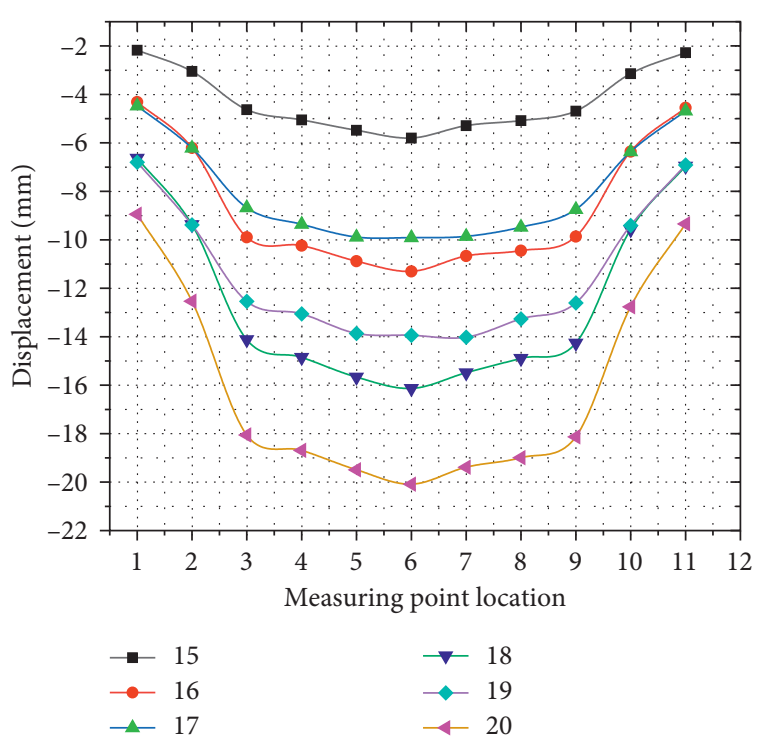

(b)

Figure 10: The maximum displacement of three segments along the width direction under various working conditions. (a) Three-tenon type segments. (b) Four-tenon type segments.

Comparing the working conditions $(6,8,10,16,18$, and 20), where the ring joint is dislocated, the displacement adjustment phenomenon of the segment appears, and the displacement adjustment ability decreases according to $S_{t}$ and $S_{f}$. The decrease of $S_{t}$ is greater. Generally speaking, when no dislocation occurs, the respective displacement adjustment coefficients are the same in the different circumferential segment joint arrangements (e.g., working conditions 5, 7, 15, and 17).

In the working condition that does not produce a dislocation, the maximum static friction that can be provided between the rings is greater than the vertical vault load. This indicates that the timing of the dislocation is the key to the application of the longitudinal force to adjust the displacement and, for the four-tenon type, compared with the three-tenon type, the reduction of the displacement adjustment ability of the three-tenon type is smaller. This indicates that, under the same vertical vault load condition, the four-tenon combined segment has a stronger displacement coordination ability and better antideformation ability than the three-tenon type combination segment when circumferential joint is dislocated.

Figure 10 presents the displacement diagram of the width direction of the segment. When the vertical load is $600 \mathrm{kN}$, the values of $S_{t}$ and $S_{f}$ are compared under each working condition and the effect of the longitudinal force displaces the middle target segment coordinately with the adjacent segments on both sides. As a matter of fact, 
enhancement in displacement distribution occurs due to the application of longitudinal force, while the segments on both sides deform together, the load is shared, and the vertical displacement of the middle target B3 segment is also reduced. Compared with $S_{t}$ and $S_{f}$ under working conditions with longitudinal force of $600 \mathrm{kN}$ and different vertical load, $t$, it can be seen that the displacement adjustment ability of the segment is weakened with the increase of vertical load. This is due to the dislocation between the rings.

\subsection{The Influence of the Longitudinal Force on the Bending} Moment of the Segments under the Connection between the Different Rings. Figure 11 illustrates the bending moments of the four-tenon segment and the three-tenon segment between the rings in the width direction. This defines the parameter bending moment distribution coefficient $M$ for evaluating the bending moment distribution capacity between the rings:

$$
M=1-\frac{M_{1}}{M_{2}} .
$$

In equation (2), $M_{1}$ is the value of the bending moment of the middle segment along the width direction in the combined segment, while $M_{2}$ is the value of the bending moment of the single segment along the width direction. $M_{t}$ is the three-tenon type universal B3 block bending moment distribution coefficient and $M_{f}$ is the four-tenon type universal B3 block bending moment distribution coefficient.

Figure 12 illustrates the change of the bending moment adjustment coefficient. The changes of the $M_{t}$ and $M_{f}$ values in Figures 9 and 12 are similar to $S_{t}$ and $S_{f}$. The $M_{t}$ and $M_{f}$ values all show different degrees of decrease as the load increases. Compared with the results of a single segment and combined segments, the bending moment of the middle target segment is distributed to both sides of the segment. This reduces the value of the bending moment that the segment should bear. Consequently, the value of both sides increases.

Figure 13 shows the distribution of the bending moment of the B3 segment along the width direction under two different mortise and tenon arrangements. Compared with the working conditions where the dislocation does not occur, the difference in the bending moment distribution coefficient is small. This indicates that the key to the reduction of the distribution capacity is that when the ring-to-ring dislocation does not occur, the bending moment distribution capacity remains unchanged and is not affected by the external loads. When the ring joints are dislocated, the bending moment is distributed as the vertical load increases and the capacity is reduced. At the same time, the comparison of the bending moment distribution coefficients under these working conditions illustrates that the bending moment distribution capacity of the four-tenon segment is the same as that of the three-tenon segment when the vertical load of the structure is small. Consequently, the bending moment of the four-tenon tube segment is more fully distributed with the occurrence of dislocation.
4.3. The Influence of the Longitudinal Force on the Opening Deformation of the Circumferential Joint of the Segment Structure. Extract the circumferential joint opening data in $\mathrm{J} 1$ and J2. Figure 14 presents the opening of the ring joint of the two combined segment ring structures under the longitudinal force of $0 \mathrm{kN}$. Before the vertical load reaches $1400 \mathrm{kN}$, the opening of the ring joint of the segment increases linearly. However, the three-tenon segment increases more than the four-tenon type. When the load reaches $1400 \mathrm{kN}$, the opening between the two segments tends to be stable.

Due to the arrangement of the mortises and tenons between the rings, after the mortises and tenons contact, the ring joint of the segment gradually changes from a staggered opening of the ring joint to a stabilized opening of the ring joint, indicating that the opening deformation of the ring joint of the segment that finally stagnates is not affected by the load of the vault. Comparing the two segment ring joint types, it is observed that the stable value of the four-tenon segment ring joint opening under the same vertical load is smaller. This indicates that the four-tenon arrangement between the rings is more conducive to controlling the opening and the deformation of the segment ring joint. The difference in the layout of the mortise and tenon will not delay the timing of the opening of the ring joint.

Figure 15 illustrates the change in the circumferential joint opening under the longitudinal force action. More specifically, $600 \mathrm{kN}$ represents the working condition of the $600 \mathrm{kN}$ longitudinal force at the J1 position. Under the same vertical load, the circumferential joint opening of the segment decreases with the increase of the longitudinal force. Due to the particularity of the mortise and tenon between the rings, the ring joints of the segments gradually overcome the maximum static friction between the rings to cause interring dislocation. In this way, they gradually transform into an expansion and deformation between the rings. As a result of the ring joint opening, the ring joints no longer make contact. At the same time, the area of the contact surface of the mortise and tenon is reduced. Therefore, the corresponding distribution and adjustment ability is weakened. When comparing the opening amount of the circumferential joint under different circumferential joint structures, when the opening deformation of the circumferential joint begins to occur, the increasing rate of the circumferential joint opening amount of the four-tenon segment and the opening amount after the final stabilization is smaller.

\section{Discussion}

Figure 16 shows that the segment structure undergoes four main stress stages under the action of the vertical loads:

(1) Stage 1: the dominated stage of the circumferential joints contact. Here, the circumferential joints are in complete contact and the structure is deformed as a whole. The general B3 block is mainly constrained by the circumferential joint surfaces on both sides. The key to controlling the internal force distribution 


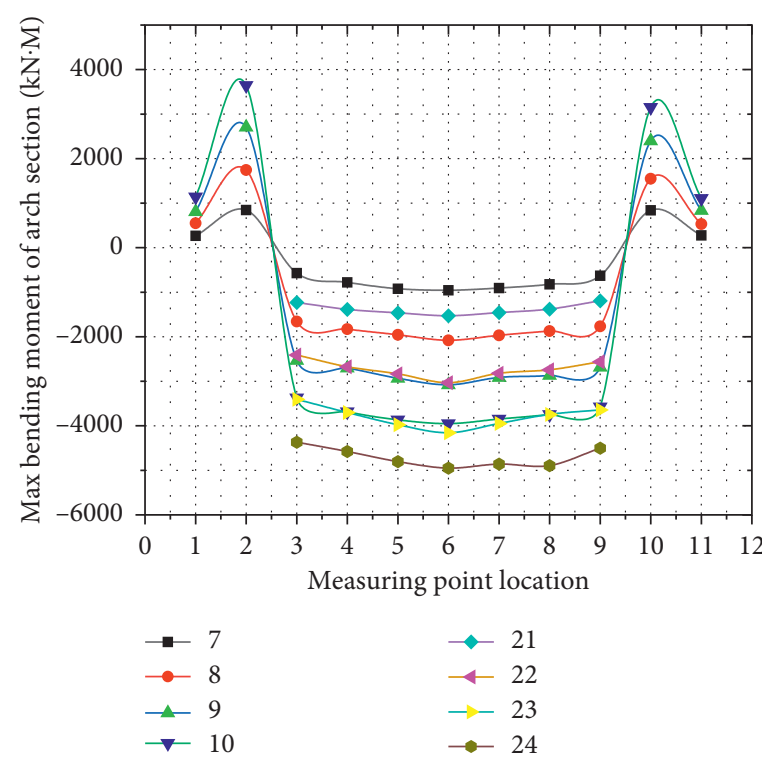

(a)

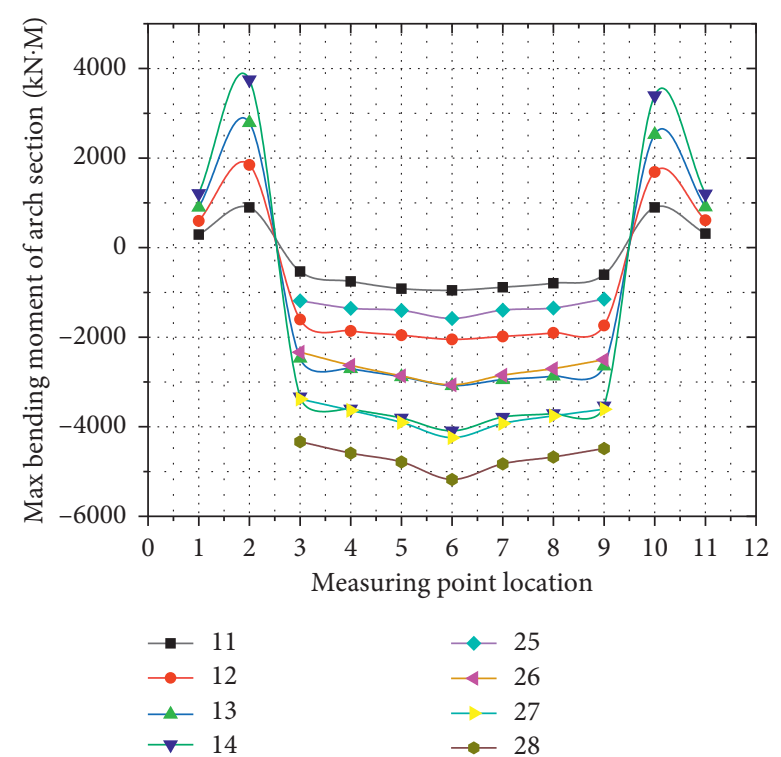

(b)

FIGURE 11: The maximum bending moment along the width of single segment and three segments under vertical loads. (a) Three-tenon type segment along width direction. (b) Four-tenon type segment along width direction.

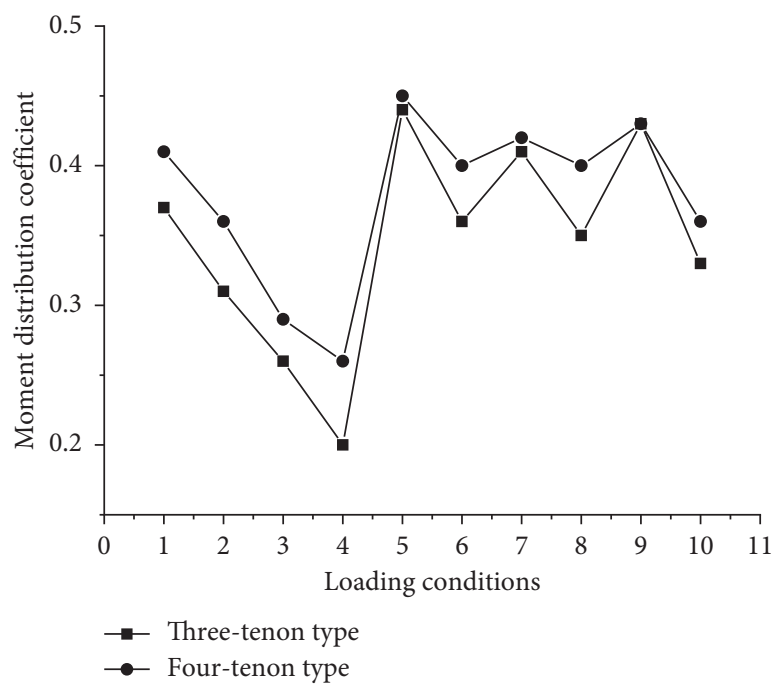

Figure 12: Results of moment adjustment coefficient.

ability is the maximum static friction between the rings.

(2) Stage 2: the dominated stage of the ring joint surface of the outer surface of the tenon. When dislocation occurs, due to the existence of the mortise and tenon structure, the mortise and tenon contact surface will slide outward along the surface of the tenon. This will cause the ring joint to open. Due to the deformability of the concrete, there will be a certain friction between the ring joints; this friction is smaller. In this process, the bending moment distribution capacity is reduced and the displacement is gradually uncoordinated. The angle between the contact points of the mortise and tenon in the vertical direction is small. The opening of the circumferential joint is extremely small. This stage can be summarized as the second stage, which is ideal. Here, only the mortise and tenon bear the vertical shearing force. It can be judged by the timing of the ring joint opening.

(3) Stage 3: the stage dominated by the mortise and tenon. In this stage, the mortise and tenon bear the vertical shearing force, transmit the bending moment, and coordinate the vertical displacement. As the opening of the circumferential joint gradually increases, the area of the contact surface of the mortise and tenon decreases, and the coordination of 


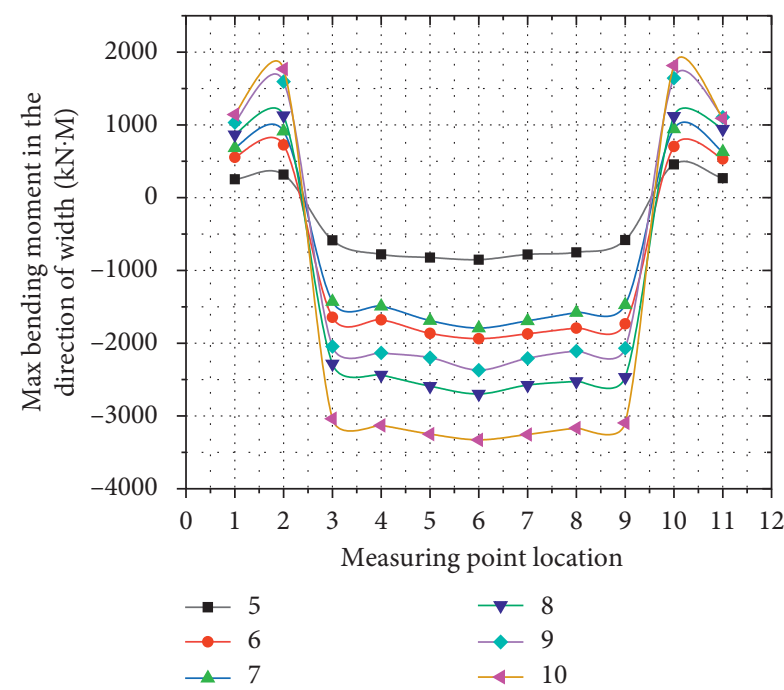

(a)

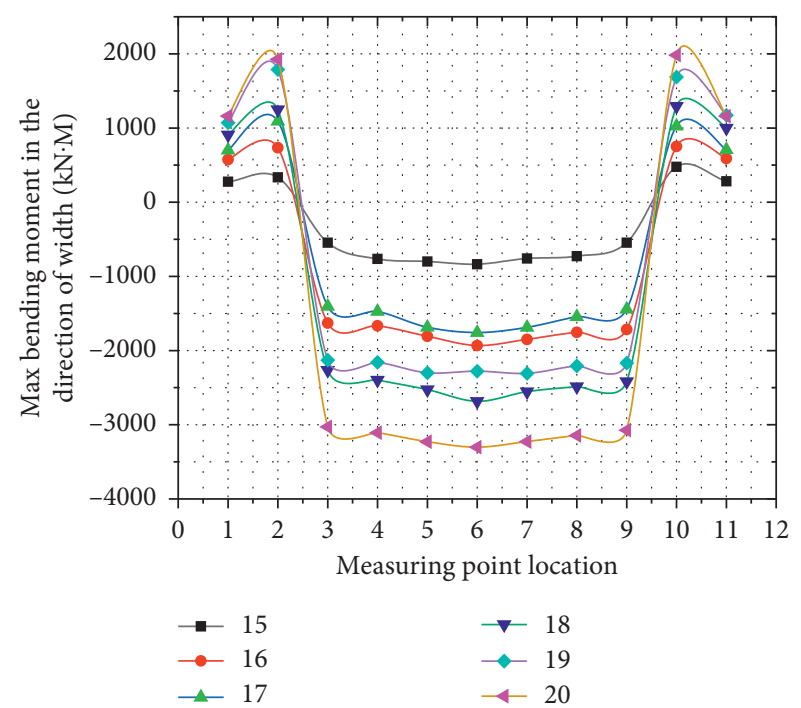

(b)

Figure 13: The maximum bending moment along the width of segments under various working conditions. (a) Three-tenon type segment. (b) Four-tenon type segment.

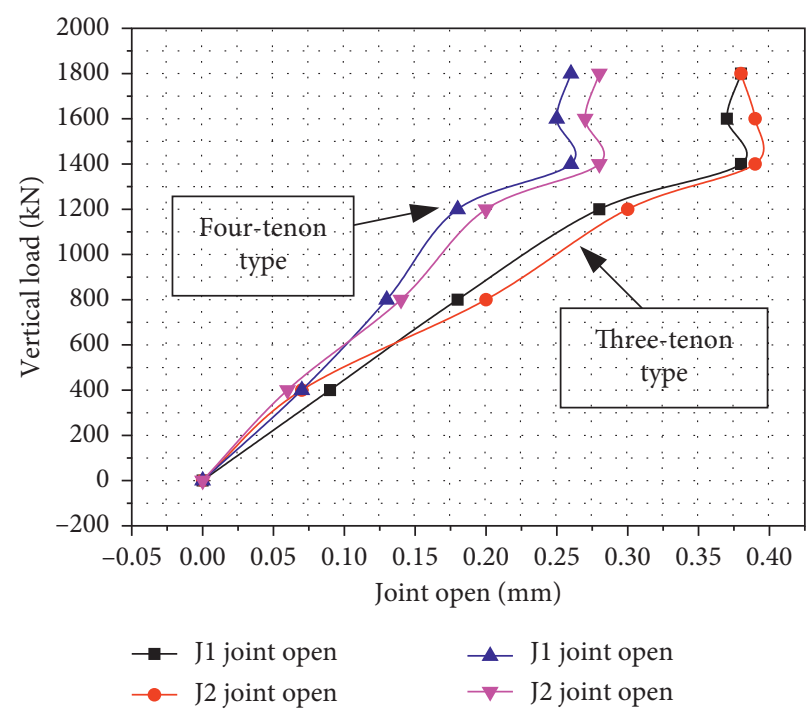

FIGURE 14: The open amount without longitudinal force.

the bending moment distribution and displacement is further reduced. At this stage, the opening of the circumferential joint is larger.

(4) Stage 4: the stable stage of the combined segment. As the vertical load increases, the structure distribution and coordination ability remain stable at a node. At this time, the opening value of the ring joint remains constant.

For two B3 segments with different joint forms, in the initial stage of the structural loading, because the friction coefficient of the concrete surface is the same, the friction force generated under the same longitudinal force is the same and the contact area of the two segments is almost the same. When the structural ring joints are not staggered, the restraint ability of the two segments on the middle B3 block is the same and the displacement adjustment is the same as the bending moment distribution ability. The mortises and tenons do not bear the load. However, as the circumferential joint opens, the restraint method on both sides changes. For a four-tenon joint, the outer surface of the four-tenon structure is mainly used. Its restraining ability is stronger than that of a three-tenon joint, so the internal force and deformation distribution ability are stronger. In addition, the corresponding distribution ability is better when the structure is finally stable. 


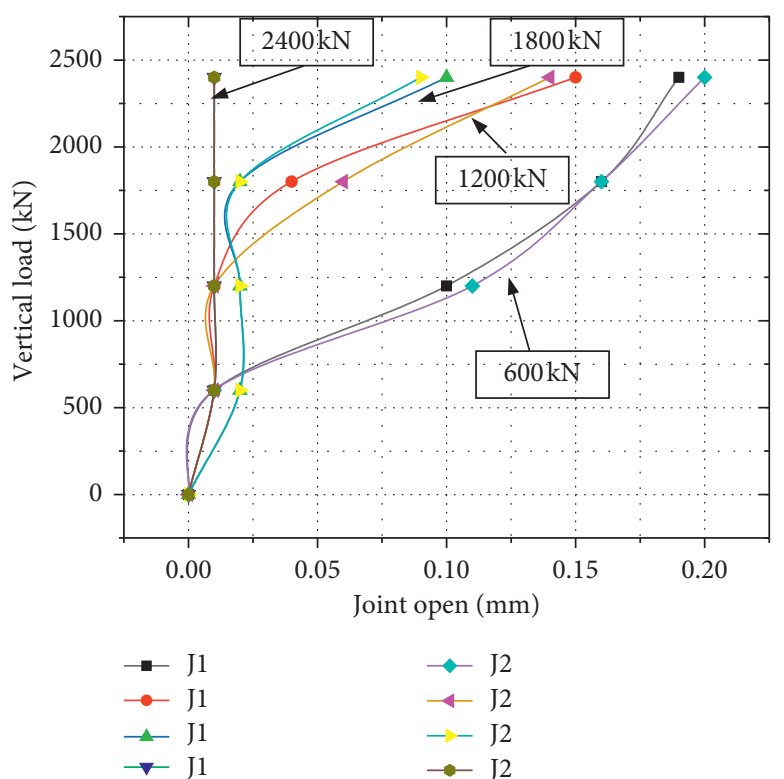

(a)

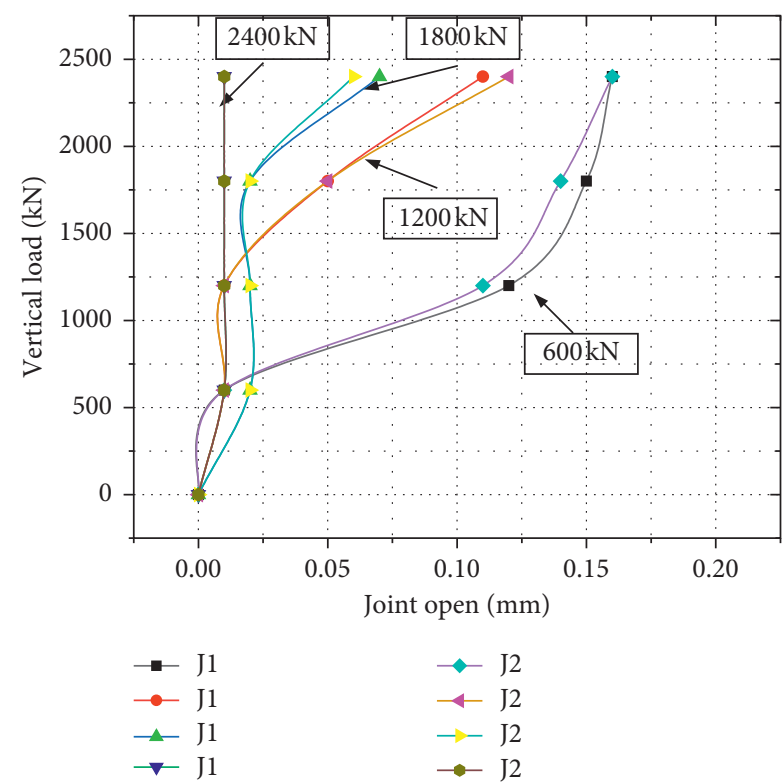

(b)

FIgURE 15: The open amount under different longitudinal forces. (a) Three-tenon type segment. (b) Four-tenon type segment.

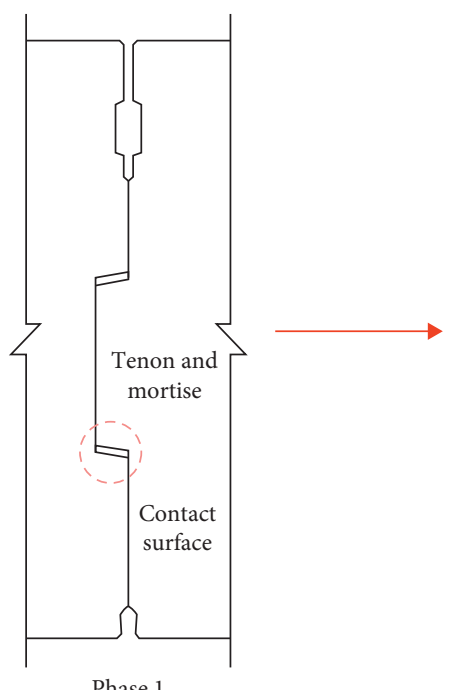

Phase 1

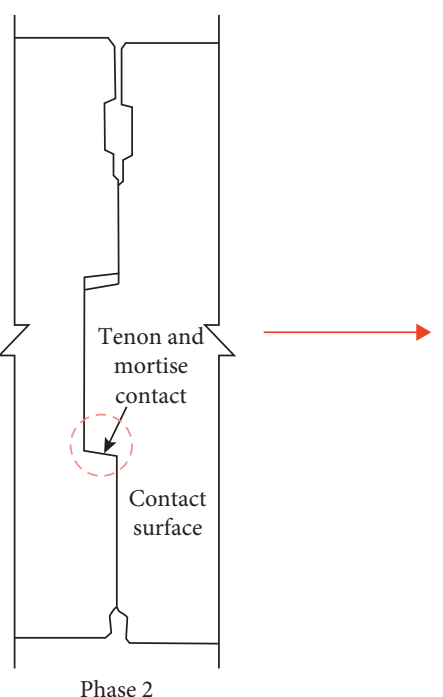

Phase 2
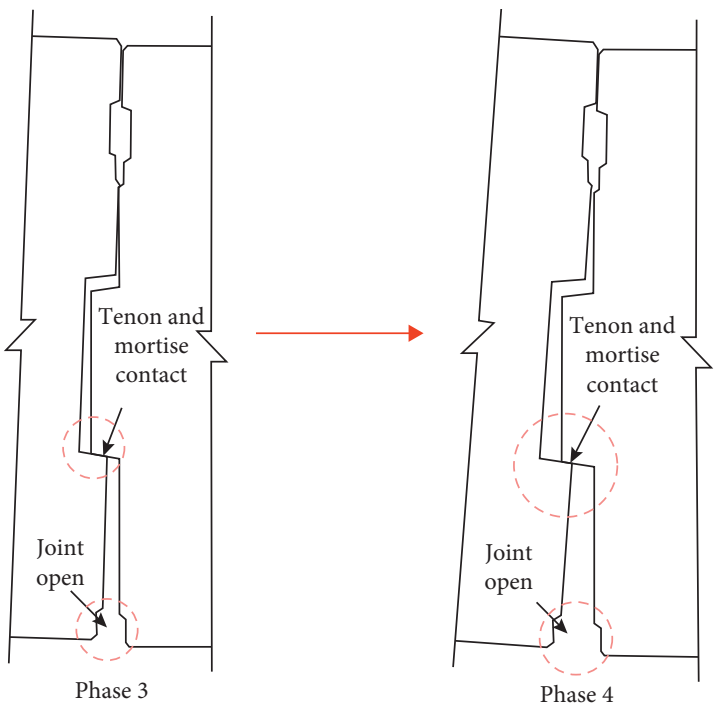

FIGURE 16: Schematic diagram of open amount.

\section{Conclusions}

This paper uses the local structural prototype loading test to study the interaction mechanism of the shield tunnel segment structure under the influence of a longitudinal restraint on the Foshan Intercity Railway's Sutong GIL Power Pipeline Tunnel and Shiziyang Tunnel Projects. The influence of the longitudinal restraining force on the internal force transfer characteristics and the displacement coordination mechanism between the segments and the internal force and deformation transmission methods of the segments under different ring connections are compared.
There are four primary conclusions of this investigation:

(1) Through the bending moment distribution coefficient and displacement, the coordination coefficient evaluates the overall bending moment distribution and deformation coordination ability of the combined segment structure.

(2) The way that the longitudinal force affects the internal force distribution and displacement coordination ability of the structure is to make the ring joint surface fully contact. In this way, the intuitive indicators of the contact status are the amount of 
interring dislocations and ring joint openings. With the opening of the joint, the transfer effect between the middle segment and the two sides of the segment gradually comes through the mortise and tenon contact surface.

(3) When there is no dislocation and expansion between the rings, the four-tenon segment has the same internal force distribution and deformation coordination capabilities as the three-tenon segment. However, the four-tenon type segment has a stronger internal force distribution and overall antideformation ability when circumferential joint opening occurs. In addition, the opening rate of the ring joint is lower and the opening amount is smaller after stability.

(4) In engineering, the loss of the longitudinal restraint force during the construction and operation period is reduced. Due to the change in the longitudinal force, the displacement of the combined segment ring and the redistribution of the internal force will affect the stability of the segment structure and the composite pipe stress concentration occurs in some areas of the segments. For different joint forms, the vault is generally a B3 block. The distribution capacity between the segments should be fully considered in the design of the segment structure. When the fourtenon segment is under the load of the dome, its distribution capacity is more sufficient, and the joint opening is smaller.

\section{Data Availability}

No data were used to support this study.

\section{Conflicts of Interest}

The authors declare that they have no conflicts of interest.

\section{References}

[1] Y. Qian, Research on Non-Uniform Settlement and Real-Time Monitoring Method of Shield Tunnel, Beijing Jiaotong University, Beijing, China, 2013.

[2] J. Yin and H. Hong-wei, "Back analysis of longitudinal equivalent rigidity of shield tunnel based on longitudinal settlement curve," Rock and Soil Mechanics, vol. 36, no. S1, p. 230, 2015.

[3] B. Shuai-shuai, Analysis of the Influence of Shield Construction on the Force of Segment Structure, Beijing Jiaotong University, Beijing, China, 2010.

[4] F. Duan, Analysis of the Influence of Shield Construction on the Force of Segment Structure, Anhui University of Science and Technology, Huainan, China, 2012.

[5] Z. Jin, Study on Effecting Factors of Displacement and Control Measures of Shield Tunnel Segment, Southwest Jiaotong University, Chengdu, China, 2015.

[6] J. Chen, H. Mo, and Z. Li, "Three-dimensional finite element analysis of mechanical properties of shield tunnel segments," Science, Technology and Engineering, vol. 12, no. 8, pp. 1795-1800, 2012.
[7] J. Chen and H. Mo, "Three-dimensional finite element analysis of mechanical behavior of shield tunnel segments during construction," Journal of Rock Mechanics and Engineering, vol. 25, no. S2, pp. 3482-3489, 2006.

[8] Y. Zheng, T. Bai, X. Li et al., "Numerical study on threedimensional mechanical properties of tunnel lining during construction period of Tongshi shield tunnel," Construction Technology, vol. 47, no. 1, pp. 111-115, 2008.

[9] Y. Men, L. Hu, J. Zhou et al., "Calculation and analysis of circular crack leakage considering longitudinal stress relaxation in shield tunnel," Journal of Civil Engineering, vol. 52, no. S1, pp. 99-105, 2019.

[10] S. Biwei, D. Wenqi, P. Yicheng et al., "Experimental study on moment adjustment factor of water-conveyance tunnel segment lining," Journal of Tongji University (Natural Science Edition), vol. 39, no. 7, p. 994, 2011.

[11] X. Li, B. Huang, H. Zhu et al., "Calculation method of longitudinal deformation of shield tunnel lining structure based on beam model of flexibility method," Engineering Mechanics, vol. 33, no. 4, pp. 157-165, 2016.

[12] Z. Zhang, Y. Zhu, Y. Zhu et al., "Longitudinal mechanical properties of large-section special-section shield lining structure," Journal of Tongji University (Natural Science Edition), vol. 45, no. 5, pp. 684-691, 2017.

[13] W. Zhang, D. Zibo, L. Xian et al., "Experimental study on the force-transfer property of the circumferential joints in the quasi-rectangular shield tunnel under the staggered assembling," Journal of Railway Science and Engineering, vol. 14, no. 12 , p. $2636,2017$.

[14] F. Kun, H. Chuan, and Z. Yulin, "Study on the effect of assembling method on the inner force of segmental lining for cross-river shield tunnel with lager cross-section," Engineering Mechanics, vol. 29, no. 6, p. 114, 2012.

[15] Z. Peng, W. Liu, D. Ding et al., "Study on the jacking force control of block type sealing block," Journal of Central South University (Natural Science Edition), vol. 45, no. 11, pp. 4018-4025, 2014.

[16] Y. Zhu, L. Xian, C. Zhang et al., "Experimental analysis of mechanical properties of staggered shield lining," Modern Tunnel Technology, vol. 56, no. 2, p. 123, 2019.

[17] Y. H. Zhu, X. Yangyuyu, D. Zibo et al., "Study on structural design and calculation parameters of universal ring staggered shield tunneling," Modern Tunnel Technology, vol. 55, no. 4, p. 114, 2008.

[18] Z. Yaohong, Z. Chen, L. Xian et al., "Experimental study on shear property of circumferential joint in general ring segment under the staggered assembling," Journal of Railway Science and Engineering, vol. 14, no. 2, p. 315, 2017.

[19] Y. Zhu, X. Liu, C. Zhang et al., "Experimental analysis of mechanical properties of shield lining with staggered joints," Modern Tunnel Technology, vol. 56, no. 2, pp. 123-133, 2019.

[20] W. Zhang, G. Wenyuan, and L. Hongliang, "Research on bending moment transfer coefficient of disaster resistance performance of shield tunnel structure," Construction Technology, vol. 48, no. 9, p. 52, 2019.

[21] X. Liu, Z. Weixi, and W. Dongfang, "Experimental study on shear performance of longitudinal joint in quasi-rectangular shield tunnel," Journal of Railway Science and Engineering, vol. 13, no. 9, p. 1767, 2016.

[22] L. Dongmei, C. Zhengjie, and Y. Zhihao, "Test and analysis of shear resistance of loop joints of pipe segments in Shanghai Yangtze river tunnel," Underground Engineering and Tunnel, vol. 1, no. 1, p. 15, 2011.

[23] Y. Tang, Analysis on Longitudinal Mechanical Behavior of Segmental Lining of Complicated Underwater Shield Tunnel 
under Special Circumstances, Southwest Jiaotong University, Chengdu, China, 2017.

[24] W. Zhang, Q. Zhang, and G. Zhang, "Research on joint bolt selection and flexural stiffness of shield tunnel of Tianjin Binhai Z2 line," Journal of Geotechnical Engineering, vol. 41, no. S1, pp. 113-116, 2019.

[25] S. Liu, F. Kun, C. He et al., "Study on the flexural mechanical model of the joint of large section shield tunnel," Engineering Mechanics, vol. 32, no. 12, pp. 215-224, 2015.

[26] A. Salemi, M. Esmaeili, and F. Sereshki, "Normal and shear resistance of longitudinal contact surfaces of segmental tunnel linings," International Journal of Rock Mechanics and Mining Sciences, vol. 77, pp. 328-338, 2015.

[27] L. Guo, X. Yang, and Y. Qiu, "Shield segment lining vertical heterogeneity equivalent continuous model," Journal of Research in Urban Rail Transit, vol. 20, no. 4, pp. 17-22, 2017.

[28] S. Cao, F. Kun, X. Liu et al., "Analysis of the influence of longitudinal forces on the internal force distribution mechanism of shield tunnel segment structure-a case study of sutong GIL power tunnel project," Tunnel Construction (Chinese and English), vol. 39, no. S2, pp. 154-162, 2019.

[29] Y. Qiu, F. Kun, C. He et al., "Failure test of local prototype structure of staggered and piecework pipe lining of shield tunnel," Chinese Journal of Civil Engineering, vol. 52, no. 4, pp. 98-108, 2019.

[30] Y. Qiu, C. He, F. Kun et al., "Local prototype structure loading test of shield tunnel segment lining effect," Chinese Journal of Highways, vol. 30, no. 8, pp. 156-163, 2017. 